\title{
ANALYSING A RESILIENCE DEVELOPMENT PROGRAM: WHO BENEFITS
}

\author{
Jonathon Heatherl, Elizabeth Shannon', Sue Pearson' \\ 1. University of Tasmania, Hobart, Tasmania, Australia \\ Correspondence: e.shannon@utas.edu.au
}

\section{ABSTRACT}

\section{OBJECTIVE:}

This article presents findings from an analysis of resilience and resilience development.

\section{DESIGN:}

Convergent, mixed-methods research used an online survey to gather data from participants in a resilience development program, in combination with a small number of semi-structured interviews with managers.

\section{SETTING:}

The research was carried out on public sector health and human services managers and staff, during a time of 'downsizing' and organisational restructuring.

\section{MAIN OUTCOME MEASURES:}

The Wagnild Resilience Scale was used to measure resilience levels and their association to respondent demographic, educational and professional groupings.

\section{RESULTS:}

Interviews with senior managers found a consensus of opinion that resilience was important; and the resilience development program either had, or potentially had, benefits for their workforce. Perceptions about exactly who would benefit differed between senior managers and participants in the program. Participant survey results indicated that respondent characteristics lage, occupational group, highest level of education and departmental role) were associated with differing levels of resilience.

\section{CONCLUSIONS:}

This study found that resilience development may benefit two groups of employees in particular: non-nursing staff under 50 years of age, and managers. These findings add to the body of knowledge associated with staff resilience development, organisational change management and organisational learning. These results inform health service manager practice by suggesting potential target groups for resilience development.

\section{KEYWORDS}

resilience; human resource development; change management; health and human services; leadership development

This paper examines a common experience within Australian public sector health and human services organisations: the 'in-house' development and implementation of resources and programs to help support staff through downsizing and organisational change. In 2015, a series of public sector downsizing events in the (then) Tasmanian Department of Health and Human Services (DHHS) led to the development of a range of 'resilience' resources by the Leadership and Management Development Unit (LAMDU). A series of workshops were held to introduce these resources and an accompanying resilience coaching program was provided. Research was undertaken to investigate the level of resilience amongst program participants and the perceptions of senior managers as to the effectiveness of the program. 


\section{INTRODUCTION}

\section{DRAWING ON THE LITERATURE, DEVELOPING RESILIENCE RESOURCES}

While individual reactions to organisational change are often complex and multi-faceted, studies suggest that change requiring staff downsizing leaves employees less motivated to contribute to organisational success and less willing to apply discretionary effort to accomplishing tasks.[1] 'Normal' responses to organisational change and downsizing may also include anger and overt resistance.[2] Poorly managed change is linked to a rise in employee stress, health issues and voluntary departures.[3] In health facilities, organisational change initiatives have also been linked to negative patient outcomes.[4]
Managing change in a downsizing environment requires both the ability to work through conflict and the ability to build consensus.[5] The negative effects on staff performance and health caused by organisational downsizing can be mitigated, at least in part, through staff resilience. Specifically, building employee resilience has been shown to increase employee engagement and support for change.[6]

In the LAMDU resources, resilience was defined as 'the capacity to cope with change and challenge and bounce back during difficult times'. [7] While initially inspired by similar 'resilience through downsizing' work in the United Kingdom,[8] the LAMDU focus on staff resilience was structured along the lines of 'three capitals': human, social and psychological or identity capital.[9]

TABLE 1. CONCEPTUAL OVERVIEW OF BUILDING STAFF RESILIENCE

\begin{tabular}{|l|l|l|}
\hline $\begin{array}{l}\text { HUMAN CAPITAL } \\
\text { (SIGNATURE STRENGTHS) }\end{array}$ & $\begin{array}{l}\text { SOCIAL CAPITAL } \\
\text { (BUILDING BRIDGES) }\end{array}$ & $\begin{array}{l}\text { PSYCHOLOGICAL CAPITAL } \\
\text { (SELF MATTERS) }\end{array}$ \\
\hline $\begin{array}{l}\text { - Existing education, experience, } \\
\text { knowledge, skills and abilities } \\
\begin{array}{l}\text { - Refreshing career strengths with } \\
\text { SMART personal goals }\end{array}\end{array}$ & $\begin{array}{l}\text { - Friends and family } \\
\text { - Professional networking and } \\
\text { resilient role models }\end{array}$ & $\begin{array}{l}\text { Hope - the will and the way - } \\
\text { expect the best and have a plan to } \\
\text { achieve it }\end{array}$ \\
& $\bullet$ Community and civic engagement \\
& $\begin{array}{l}\text { Efficacy - 'can do' - the confidence } \\
\text { to succeed }\end{array}$ \\
& $\begin{array}{l}\text { Resiliency - bouncing back and } \\
\text { beyond }\end{array}$ \\
\hline
\end{tabular}

Human capital is the experience and expertise that an individual brings to their working life.[7] The DHHS resources describe these as 'signature strengths': a person's individual way of thinking, feeling and behaving that helps them accomplish their goal. The 'Signature Strengths' workbook guided employees through the process of looking at their education, knowledge, skills and abilities; what (if anything) they would like to develop; and where they want to be in the future.[10] It was stated upfront that the expected results of these exercises would be to develop the kind of 'career optimism' that is positively related to success.[11]

Social capital provides the networks and relationships that support individuals in their home, work and community. [7]
The 'Building Bridges' workbook contained exercises that not only looked at harmonising the competing demands employees may face between home and work, but also strategies for managing the boundaries between. These included the development of both formal and informal professional networks and the connections that employees could make to the broader community.[12]

Developing psychological capital speaks to the links between individual psychological and physical health; organisational health and culture; and productivity.[13] The HERO (hope, efficacy, resiliency and optimism) attributes of psychological capital are particularly valuable in times of change.[7] 
The 'Self Matters' workbook encouraged participants to explore the concept of hope as a positive, personal drive, directed by individual agency ('the will') and planning ('the way') to meet challenging situations.[14] Similarly, efficacy was defined as a 'can do' attitude that motivates the individual to choose and welcome challenges and to use their strengths and skills to meet them. [7] Resiliency was defined as not only the ability to bounce back from adversity, but also the will to go beyond the normal, to strengthen positive outlook.[15] Finally, an optimistic style was defined as supporting resilience as it enables the individual to adopt 'can do' thinking, and experience the positive emotions that come with success.[16] The 'Self Matters' workbook suggests ways of cultivating an optimistic style by exercising more control over thinking that may be self-defeating or undermining.[8]

The LAMDU resilience resources were made available on the DHHS intranet as well as the Department of Premier and Cabinet internet page. These included the three resilience workbooks [10, 12, 14] and two guides for managers and coaches. [17, 18] Although the activities in the resilience workbooks could be completed individually, staff were encouraged to work with a coach or their manager and work team. Volunteer resilience coaches were recruited to work with other employees, using the workbooks. The inhouse resilience video-conference series attracted an enrolment of over 200 participants, while face-to-face workshops were also provided to over 200 DHHS staff.

\section{METHODS}

The appraisal of the LAMDU resilience program was undertaken by a University of Tasmania student, recruited through the State Service Internship Program. During the ten-week internship, a convergent mixed-method research design was used for the purpose of (1) examining the levels of resilience amongst resilience program participants and (2) assessing the effectiveness of the resilience program, in the opinion of senior managers. 'Mixed-methods' was chosen as a pragmatic approach to gathering in-depth information from a few, key senior managers (through interview) as well as a more limited set of information from a staff across the state (through online survey).

When designing the online survey, a number of potential instruments to measure employee resilience were considered. After conducting a review of each instrument, it was decided that the Wagnild (2013) 25-Item Resilience Scale (RS) would be utilised.[20] The RS was chosen due to the fact that it provided a balance between survey length and quantitative data detail. The primary quality of the RS is that it is simple and straightforward for survey respondent to complete and provides the researcher with clear and precise quantitative data.[21]

Along with conducting the RS survey, five interviews were conducted with Senior Managers who had participated in the resilience program. The interviews were conducted in a semi-structured manner and their duration varied between 15-30 minutes. In each interview a number of set questions were asked about the interviewees' knowledge of, interaction with, and opinion of the resilience program. Each interview was recorded, transcribed and validated with the interviewee. In order to analyse the interviews a thematic analysis was conducted, and a number of thematic similarities were identified in the responses of the interviewees.[19]

\section{RESULTS}

\section{SURVEY RESULTS}

The RS survey was emailed to 291 staff, who were known to have attended one of the resilience events in the last 12 months, and a total of 82 responded ( $28 \%$ response rate). In addition to completing the RS survey, respondents were asked to classify themselves in relation to their gender, age group, role in the department, highest level of education and occupational group. Table 2 provides respondent demographics.

Students t test and analysis of variance (ANOVA) were used to compare mean resilience scores for individual item scores, total resilience and the two dimensions of 'acceptance of self' and 'life and personal' competence across age, sex, occupation, education and role categories. Results tables report comparisons less than or equal to $P=0.10$. Means $(M)$ and standard deviations (sd) are reported.

Only $6 \%$ of survey respondents had RS scores that indicated low levels of resilience (total score of $<121$ ). Another $46 \%$ of respondent RS scores indicated moderate resilience (total score 121-145). A slightly larger group (48\% of all respondents) registered scores that indicated high levels of resilience (total score 146-175). The mean score for the total 
sample was 144.6 (sd 15.2), showing moderate resilience. However, survey results also indicated that some respondent demographic and workplace characteristics were associated with differing levels of resilience. Survey data analysis indicated that there were no significant differences found on any resilience measures at $p \leq 0.10$ for comparisons between men and women. Comparisons across the age groups on selected resilience measures at $P$ $\leq 0.10$ are shown in Table 3 . Being 50 years or older was generally associated with increasing resilience.

\section{TABLE 2. SURVEY RESPONDENT DEMOGRAPHICS ( $\mathrm{N}=82)$}

\begin{tabular}{|l|l|}
\hline GENDER (N, \%) & $15(18.3)$ \\
\hline Men & $67(81.7)$ \\
\hline Women & \\
\hline Age (N, \%) & $9(11.0)$ \\
\hline $20-39$ & $22(26.8)$ \\
\hline $40-49$ & $43(52.4)$ \\
\hline $50-59$ & $8(9.8)$ \\
\hline $60+$ & \\
\hline Occupational group (N, \%) & $31(37.8)$ \\
\hline Administration and clerical [A\&C] & $22(26.8)$ \\
\hline Allied health professionals [AHP] & $27(32.9)$ \\
\hline Nursing and midwifery [N\&M] & $2(2.4)$ \\
\hline Medical and paramedical [M\&P] & \\
\hline Highest level of education (N, \%) & $44(37.8)$ \\
\hline Postgraduate university [PG] & $21(26.8)$ \\
\hline Undergraduate university [UG] & $17(32.9)$ \\
\hline Other qualification [O] & $14(40.2)$ \\
\hline Role in department (N, \%) & $23(28.0)$ \\
\hline Senior manager [SM] & $12(14.6)$ \\
\hline Middle manager [MM] & $33(40.2)$ \\
\hline Front-line manager [FM] & \\
\hline Not a manager [NM] & \\
\hline
\end{tabular}


TABLE 3. COMPARISON OF MEAN SCORES ON SELECTED RESILIENCE MEASURES ACROSS AGE GROUPS

\begin{tabular}{|l|l|l|l|l|l|}
\hline AGE & $\begin{array}{l}20-39 \\
(\mathbf{N}=9)\end{array}$ & $\begin{array}{l}40-49 \\
(\mathbf{N}=22)\end{array}$ & $\begin{array}{l}50-59 \\
(\mathbf{N}=43)\end{array}$ & $\begin{array}{l}\text { 60 AND } \\
\text { OVER } \\
(\mathbf{N}=8)\end{array}$ & $\begin{array}{l}\text { P } \\
\text { VALUE }\end{array}$ \\
\hline & $\mathbf{M} \pm \mathbf{s d}$ & $\mathbf{M} \pm \mathbf{s d}$ & $\mathbf{M} \pm \mathbf{s d}$ & $\mathbf{M} \pm \mathbf{s d}$ & \\
\hline I seldom wonder what the point of it all is & $4.78(1.86)$ & $4.41(1.62)$ & $5.47(1.18)$ & $5.13(0.64$ & 0.032 \\
\hline I keep interested in things & $5.78(0.44)$ & $5.68(0.84)$ & $6.12(0.88)$ & $6.38(0.52)$ & 0.090 \\
\hline $\begin{array}{l}\text { I do not dwell on things that I can't do } \\
\text { anything about }\end{array}$ & $4.43(1.12)$ & $4.23(1.41)$ & $5.12(1.22)$ & $5.50(0.93)$ & 0.014 \\
\hline Acceptance of self and life summary score & $41.78(7.08)$ & $41.59(4.55)$ & $44.83(6.51)$ & $46.37(3.54$ & 0.080 \\
\hline
\end{tabular}

Comparisons across occupations on selected resilience measures are shown in Table 4. Participants employed in nursing and midwifery tended to be more resilient than those in the other occupations with exception to the first item "Keeping interested in things is important to me".

In table 5 comparisons across educational categories are shown for selected resilience measures. Those with undergraduate level of education tended to report higher resilience on these items.

Comparisons across roles only differed on the item "I usually manage one way or another" $(p=0.02)$ means and standard deviations reported respectively (front-line manager; $5.67 \pm 0.89$, middle manager; $5.87 \pm 0.82$, senior manager; $5.07 \pm 1.64$ and not a manager; $6.09 \pm 0.81$ ).

TABLE 4. COMPARISON OF MEAN SCORES ON SELECTED RESILIENCE MEASURES ACROSS OCCUPATIONAL GROUPS

\begin{tabular}{|l|l|l|l|l|}
\hline OCCUPATION & $\begin{array}{l}\text { ADMINISTRATION } \\
\text { 8. CLERICAL } \\
\text { (N=33) }\end{array}$ & $\begin{array}{l}\text { ALLIED } \\
\text { HEALTH } \\
\text { (N=22) }\end{array}$ & $\begin{array}{l}\text { NURSING AND } \\
\text { MIDWIFERY } \\
\text { (N=27) }\end{array}$ & P VALUE \\
\hline $\begin{array}{l}\text { Keeping interested in things is important to } \\
\text { me }\end{array}$ & $6.48(0.67)$ & $6.32(0.78)$ & $6.0(0.83)$ & 0.051 \\
\hline I take things one day at a time & $4.33(1.53)$ & $4.77(1.63)$ & $5.22(1.12)$ & 0.065 \\
\hline I can usually find something to laugh about & $5.67(0.96)$ & $5.68(1.08)$ & $6.22(0.89)$ & 0.061 \\
\hline $\begin{array}{l}\text { I do not dwell on things I can't do anything } \\
\text { about }\end{array}$ & $4.39(1.14)$ & $4.77(1.34)$ & $5.41(1.28)$ & 0.009 \\
\hline $\begin{array}{l}\text { It's okay if there are people who don't like } \\
\text { me }\end{array}$ & $5.42(1.0)$ & $5.09(1.48)$ & $5.85(0.99)$ & 0.071 \\
\hline
\end{tabular}




\begin{tabular}{|l|l|l|l|l|}
\hline EDUCATION & $\begin{array}{l}\text { POSTGRADUATE } \\
\text { UNIVERSITY } \\
(\mathbf{N}=\mathbf{4})\end{array}$ & $\begin{array}{l}\text { UNDERGRADUATE } \\
\text { UNIVERSITY } \\
(\mathbf{N}=\mathbf{2 1})\end{array}$ & $\begin{array}{l}\text { OTHER } \\
\text { QUALIFICATIONS } \\
\text { (N=17) }\end{array}$ & $\begin{array}{l}\text { P } \\
\text { VALUE }\end{array}$ \\
\hline $\begin{array}{l}\text { M } \pm \text { SD } \\
\text { anyone else }\end{array}$ & $5.45(1.37)$ & $6.10(0.83)$ & $6.0(1.06)$ & 0.082 \\
\hline I seldom wonder what the point of it all is & $4.82(1.54)$ & $5.71(0.90)$ & $4.94(1.39)$ & 0.050 \\
\hline $\begin{array}{l}\text { I can usually look at a situation in a number of } \\
\text { ways }\end{array}$ & $6.18(0.79)$ & $6.10(0.77)$ & $5.65(0.86)$ & 0.067 \\
\hline $\begin{array}{l}\text { I do not dwell on things I can't do anything } \\
\text { about }\end{array}$ & $4.86(1.23)$ & $5.24(1.37)$ & $4.24(1.25)$ & 0.058 \\
\hline
\end{tabular}

\section{INTERVIEW THEMES}

There were two broad themes that emerged from the thematic analysis of the interview with senior managers. The first consistent theme that emerged was a consensus that the downsizing process caused staff considerable stress. Interviewee three stated that when the reorganisation within her agency began, her staff were initially excited and eager to engage in the change process. Over time, however, people became increasingly disengaged and staff morale levels began to decrease, while stress levels began to increase. Interviewee five stated that the changes to his group had caused significant anxiety amongst staff members. Interviewee one reiterated these points but also stated that her staff felt as if they were losing control of their responsibilities because the cuts had reduced their service delivery capacity. This caused staff to become very concerned about the welfare of their clients, who were being adversely affected.

With the loss of the preventative health money, a lot of the upset conversations that I noticed were of the concern for the impact on the health and wellbeing of vulnerable Tasmanians [Interview One].

The second consistent theme that emerged was the belief that the resilience program either had, or could have, benefits for the workforce. Interviewee one stated that a number of the activities in the workbooks had been very useful for facilitating conversations between her staff, and in her staff forming closer bonds. The program also resulted in her staff having a greater consideration of resilience and greater tolerance of other people's ways of dealing with change. Interviewee two stated that there had been a distinct positive change in atmosphere across her team which coincided with the trial run of the program. She thought that the program's content was very applicable and that the results of the program exceeded her expectations:

I would suggest that staff are resonating with the concept of being supported and I think that this is a very strong take home message. If we make that investment in our staff then value to the organisation naturally follows [Interview Two].

The senior managers differed as to the optimal delivery method for resilience resources. Two interviewees expressed the belief that the best way to engage people in the program would be for those higher up in the department (other Senior Executives like themselves) to promote it in a 'top-down' manner:

The CEO can convince the executive team that this is something that really needs to be encouraged and supported and then you start to get it down to the general managers, heads of department, team leaders and so forth [Interview Five]. 
Interviewee four, on the other hand, felt that she would have liked to have received more 'bottom up' feedback, comment and support from the LAMDU:

As manager, what you get from the participant is just the participant's interpretation. There is no other feedback from the coordinator of the program [Interview Four].

Interviewee two also stated that she would have preferred to have seen the resilience program implemented as part of a broader change management structure. As this did not occur, she stated that the program should be utilised, in the absence of anything else. The continuity of change was a common theme:

Like every other department, we're in a constant state of change. We've gone back to being a state-wide service. Our direct line management is different to what it was previously. We are undergoing a redesign of our service model. There is lots of change [Interview Three].

The senior managers also differed as to what the optimal target group was for these resources. A belief stated by both Interviewee four and five was that the resilience program should not be a 'one size fits all' program, rather it should only be utilised for people who are clearly struggling to cope. It was not seen as relevant for senior managers:

I am not going to say that I need this. Truthfully, I would not waste my time. If I thought that one of my direct reports was struggling with resilience might suggest this [Interview Four].

\section{DISCUSSION}

The principal findings that emerged from the results were in relation to (1) the importance of resilience development; (2) targeting the most appropriate group for development; and (3) the mode of administration for development activities.

\section{THE IMPORTANCE OF RESILIENCE AND POTENTIAL BENEFITS OF PROGRAMS TO SUPPORT THIS}

This was an area of agreement amongst senior managers. While the quantitative evaluation conducted by the student Intern was hampered by the lack of baseline data with which to compare, the qualitative interviews indicated an 'in principle' support for the work.

\section{TARGETING RESILIENCE DEVELOPMENT}

On average, DHHS RS results indicated moderate resilience (144). This is the most common result for this instrument, as average scores for most samples range between 140148.[20] There was, however, some variation across the DHHS sample, based on demographic characteristics.

In direct contrast to the beliefs of some senior manager respondents, the RS results indicated that, overall, managers were not as resilient as non-managers.

Older workers (over 50 years) were generally more resilient. While it is a truism that age and experience do provide some sense of emotional stability, these results also appear to support this.

Those employed in nursing and midwifery registered higher levels of resilience. It was noted that more participants who were older were also in the occupations of nursing and midwifery, but the data suggests that there is a particular association between this occupation and higher resilience. As with age, comparisons between occupations not only assist in identifying groups with higher resilience but also groups that may benefit from being targeted for resilience development. In this case, within DHHS, younger workers and allied health professionals might form a suitable target group.

This approach contrasts with that taken by Lengnick-Hall et. al. (2011), who take a functional approach, and suggest that resilience development should focus on the 'core employee groups'. That is, those employees without which the organisation could not function, or would function poorly.[22]

\section{TOP DOWN OR BOTTOM UP ADMINISTRATION}

The senior managers interviewed were somewhat divided as to how to best deliver the resilience program - should there be more leadership from the 'top' of the organisation or more support from the 'bottom' (e.g. the LAMDU)? Reflecting the LAMDU's limited resources, the resilience program was pragmatically designed to deliver a small number of workshops, with a supporting set of coaches and online tools and resources that managers and staff could proactively interact with, at their convenience.

Additional resources would have been required for the LAMDU to play a more active role in the administration of the program and to provide support to senior managers. In an environment of fierce competition for such resources, 
this would require that resilience development become a priority within the organisation.

\section{HOW THESE RESULTS COMPARE TO OTHER STUDIES}

A 2016 Australian study confirmed the overall efficacy of workplace resilience programs in mediating the impact of organisational change, in a case study of the power distribution industry.[23] While Bardoel et. al. (2014, 283) noted 'limited efforts to design, implement and evaluate Human Resources practices to build resilience', more recent literature suggests that the concept of resilience has become more central.[24] In October 2017, a search for the terms 'resilience' or 'resilient' or 'resiliency' and 'human resource management' in peer-reviewed journal articles published since 2014, yielded 2,272 results.

The analysis of the Tasmanian resilience program was undertaken with limited staffing and, as a result, was somewhat opportunistic. A larger sample size could provide more robust conclusions about the role of resilience within Tasmanian health and human services and would have allowed analysis of the subscales of the RS. The absence of both medicine and paramedicine professions in the results leaves questions about the levels of resilience within those groups. Further research could be undertaken to explore this.

Wang et. al. (2014) found that gender, age and education level impacted on the level of self-reported resilience of Chinese banking employees but found that younger, more highly educated, male respondents were more resilient than their colleagues.[25]

In this study, the impact of education on resilience was ambiguous. Respondents with an undergraduate degree were more resilient and scored highly against three items: "I am able to depend on myself more than anyone else', 'I seldom wonder what the point of it all is' and 'I do not dwell on things I can't do anything about'. The last item listed was also significant against age, occupation and education. Postgraduates registered more highly against being 'able to look at a situation in a number of ways'. Further investigation of these dynamics may shed light on the impact of education on resilience.

\section{CONCLUSION}

This paper has confirmed the importance of resilience development within the health and human services workforce, particularly following a period of organisational change. Rather than a 'one size fits all' approach, results indicated that age, occupational group, highest level of education and departmental role may be used to target this intervention.

This paper provides an example of what a relatively modest outlay in this area can achieve, in terms of providing direction for focused interventions, and providing a return on investment.

\section{References}

1. Mishra A, Mishra K, Spreitzer K. Downsizing the company without downsizing morale. MIT Sloan Manag Rev. 2009; Spring: 39-44.

2. Day GE, Shannon EA. Leading and managing change. In: Day GE, Leggat SG, editors. Leading and managing health services: An Australian perspective. Melbourne: Cambridge University Press; 2015. p. 295304.

3. Noer DM. Healing the wounds: overcoming the trauma of layoffs and revitalizing downsized organizations. San Francisco: Jossey-Bass; 2005.

4. Timmers TK, Hulstaert PF, Leenen LPH. Patient outcomes can be associated with organizational changes: A quality improvement case study. Crit Care Nurs Quart. 2014; 37(1): 125-134.

5. Shannon E. Beyond public sector reform - the persistence of change. Aust J Public Admin. 2016; 76(4): 470-479.

6. Shin JM, Taylor S, Seo M. Resources for change: the relationships of organizational inducements and psychological resilience to employees' attitudes and behaviors toward organizational change. A Manag J. 2012; 55(3): 727-48.

7. Avolio BJ, Luthans F, Youssef CM. Psychological capital: developing the human competitive edge. Oxford: Oxford University Press; 2006.

8. Sherlock-Storey M, Moss M, Timson S. Brief coaching for resilience during organisational change an exploratory study. Coaching Psych. 2013. 9(1): 1926. 
9. Schuller T. Three capitals: a framework. In Schuller T, Preston J, Hammond C, Brassett-Grundy A, Bynner J, editors. The benefits of learning: the impact of education on health, family life and social capital. RoutledgeFalmer: London; 2004.

10. LAMDU. Leadership and Management Development Unit. Signature strengths. 2015 [cited 8 May 2019]. Available from:

http://www.dpac.tas.gov.au/_data/assets/pdf_file/0 010/309961/01_Resilience_Workbook_-

_Signature_Strengths.pdf

11. Harzer C, Ruch W. When the job is a calling: the role of applying one's signature strengths at work. J Posit Psychol. 2012 7(5); 362-371.

12. LAMDU. Leadership and Management Development Unit. Building bridges. 2015 [cited 8 May 2019]. Available from:

http://www.dpac.tas.gov.au/_data/assets/pdf_file/0 011/309962/02_Resilience_Workbook_-

_Building_Bridges.pdf

13. European Expert Group on Health in Restructuring. Innovative approaches and policy recommendations, Germany: University of Bremen; 2009.

14. LAMDU. Leadership and Management Development Unit. Self matters. 2015 [cited 8 May 2019]. Available from: http://www.dpac.tas.gov.au/_data/assets/pdf_file/0 003/309963/03_Resilience_Workbook_-

_Self_Matters.pdf

15. Luthans F, Vogelgesang GR, Lester PB. Developing the psychological capital of resiliency, HR Dev Rev 2006; 5(1): 25-44.

16. Vitalwork. Coaching for resilience: coachee handbook. Newcastle: Northumbria University; 2011.

17. LAMDU. Leadership and Management Development Unit. Resilience Leadership. 2015 [cited 8 May 2019]. Available from:

http://www.dpac.tas.gov.au/_data/assets/pdf_file/0 011/311222/Resilience_Workbook_Leaders.pdf

18. LAMDU. Leadership and Management Development Unit. Resilience coaching. 2015 [cited 8 May 2019]. Available from:

http://www.dpac.tas.gov.au/_data/assets/pdf_file/0 015/311217/04_Resilience_Coaches.pdf

19. Creswell J W. Educational research: Pearson new international edition: planning, conducting, and evaluating quantitative and qualitative research. New York: Pearson Education Limited; 2013.

20. Wagnild GM. Development and use of the Resilience Scale (RS) with middle-aged and older adults. In Prince-Embury S, Saklofske DH, editors. Resilience in Children, Adolescents, and Adults. Translating Research into Practice. New York: Springer science+Business Media; 2013. P. 151-160.

21. Wagnild GM (2003) Resilience and successful aging: comparison among low and high income older adults. J Gerontol Nurs. 2003 Dec; 42-9.

22. Lengnick-Hall CA, Beck TE, Lengnick-Hall ML. Developing a capacity for organizational resilience through strategic human resource management. HR Manag Rev. 2011 ; 21 (3): 243-255.

23. Bardoel EA, Pettit TM, De Cieri H, McMillan L. Employee resilience: an emerging challenge for HRM. Asia Pacific J HR. 2014; 52(3): 279-297.

24. Rogerson S, Meir R, Crowley-McHattan Z, McEwen K, Pastoors R. A randomized controlled pilot trial investigating the impact of a workplace resilience program during a time of significant organizational change. Int J Occup Environ Med. 2016; 58(4):329-34.

25. Wang J, Cooke FL, Huang W. How resilient is the (future) workforce in China? A study of the banking sector and implications for human resource development, Asia Pacific J HR. 2014; 52(2): 132-154. 